\title{
Feature Perspectives on Interdisciplinary Science Education
}

\section{A Problem with STEM}

\section{Michael Marder}

Department of Physics and UTeach, The University of Texas at Austin, Austin, TX 78712

\section{BACKGROUND}

Striking differences between physics and biology have important implications for interdisciplinary science, technology, engineering, and mathematics (STEM) education. I am a physicist with interdisciplinary connections. The research group in which I work, the Center for Nonlinear Dynamics at the University of Texas at Austin, is converting into the physics department home for biological physics. Many of my collaborations have been with faculty in engineering. For the past 15 years, I have been codirector of the program at the University of Texas at Austin that prepares secondary science and mathematics teachers (UTeach, 2012). The future teachers take a course on scientific research I developed and deliver together with colleagues from biology, astronomy, chemistry, and biochemistry (Marder, 2011). This background naturally makes me an enthusiastic advocate of interdisciplinary education at the secondary and undergraduate levels. Yet at the same time, I am worried by some features of what may be coming. These worries have to do with what can happen as we are all lumped together under the heading of STEM.

Undergraduate education in biology is confronted with the rapid development of the field and the urge to insert more and more recently discovered facts and ideas into introductory courses. Physics does not have this problem. Almost all physicists are happy to teach an introductory course whose structure has not changed much since 1960, and for which the content was developed before 1930. Indeed physics courses make only occasional excursions past material developed by 1960 up through the second year of graduate school. The reason is not just that physicists are resistant to change, but that the material we view as central simply has not changed for

DOI: $10.1187 /$ cbe.12-12-0209

Address correspondence to: Michael Marder (marder@mail.utexas .edu).

(C) 2013 M. Marder. CBE-Life Sciences Education (C) 2013 The American Society for Cell Biology. This article is distributed by The American Society for Cell Biology under license from the author(s). It is available to the public under an AttributionNoncommercial-Share Alike 3.0 Unported Creative Commons License (http:/ / creativecommons.org/licenses/by-nc-sa/3.0).

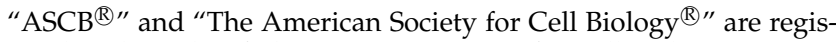
tered trademarks of The American Society for Cell Biology. decades or centuries. Our educational conservatism has some great advantages. Knowing with certainty the topics physics students will study at every level has aided the development of physics education research (PER Central, 2012), which has developed an impressive body of knowledge on instructional strategies that help students learn the best. But it means that physics will naturally resist presenting its topics in new interdisciplinary combinations.

The measured pace at which physics curriculum evolves may finally be sped up by the emergence of STEM. This acronym seems a benign and catchy way to market science, technology, engineering, and mathematics in pursuit of improving U.S. competitiveness. It also implies a challenge to physics that first hit me a few months ago as I listened to state officials in Texas explaining why undergraduate institutions should shut down inefficient parts of STEM, such as physics, so as to get more STEM graduates from efficient parts of STEM, such as biology (Reich, 2011). As we market STEM, physics and biology even risk coming into opposition, and physics is already in a weak position, partly due to developments in science education that emerged from the struggle over intelligent design.

\section{NATURE OF SCIENCE}

The debate concerning the teaching of evolution influenced the way that secondary teachers and secondary students understand the nature of science. Creation science and intelligent design presented themselves as scientific, so dealing with the attempt to inject them in public schools meant carefully defining science and explaining it well to the public (Kitzmiller v. Dover, 2005). The result was not fully balanced. It reacted to visions of what science was not, particularly the nonscience angling to enter biology textbooks. Thus, the nature of science presented to school teachers emphasizes methodological naturalism, the essential role of empirical evidence, science as social construction, and the tendency of science to change over time (Evolution and the Nature of Science Institutes, 2012).

Guarding teachers from intelligent design even evolved into an academic subdiscipline with specialized vocabulary, such as law and theory. For example, "Understanding the 
fundamental distinctions and relationships between laws and theories is essential in fully appreciating and evaluating the work of scientists while gaining fluency in the language of science" (McComas, 2003). I look at examples from physics, such as Newton's laws (fundamental theory of motion), Curie's law (an obscure empirical result in magnetism), and the quantum theory (fundamental theory of matter), and see words mainly attached to results through historical accident. Passing a vocabulary quiz on law and theory is far from understanding science (Wong and Hodson, 2008, 2010).

Given the struggle to maintain the teaching of evolution in schools, I understand why science is defined as it is. But from the vantage point of physics, it creates problems. Once students have received a good secondary education in the nature of science, they instinctively reject much of what physicists do as nonscientific. After 10 years teaching undergraduate scientific methods to future science and mathematics teachers, I have learned that, when asked to reason or experiment like physicists, many undergraduates rebel. I will single out two particular reasons.

\section{INTEGRATION OF MATHEMATICS}

Especially for theoretical physicists, but also for many experimentalists, a great deal of scientific life is occupied with mathematics. Indeed, theoretical physics, as well as theoretical chemistry, theoretical biology, parts of mechanical and chemical engineering, and other fields, becomes indistinguishable from applied mathematics. Resting in the back of most researchers' minds is the idea that at some point their calculations will be compared with experimental work-and most papers feature in the end some comparison-but the authors' time is spent almost exclusively on mathematical calculations and argumentation. Much of theoretical high-energy physics in the last 50 years has been carried out in advance of the experiments that may or may not eventually prove it correct. Did the theoretical work on the Higgs boson only become science once the European Organization for Nuclear Research found the particle? Will calculations of black hole collisions only become science if the collisions are someday observed and the calculations prove correct? I do not think so. These areas of work have been science from the start, a mode of science focusing on mathematical computations with the possibility of a future comparison with experiment.

This mode of science can be carried out at many levels, not just by candidates for the Nobel Prize. For example, given a prism made of wood and careful measurements of its weight and dimensions, one can compute the location of the water line when one floats it in a bucket. The act of carrying out these computations is a legitimate part of science, one that also uses secondary mathematics. My experience leads me to the undesired conclusion that lots of students do not like it. Some science students do not like being pressed to make use of mathematics. And many mathematics students dislike being pressed to employ ideas as a tool that they were content to know just because they were pretty.

\section{TYRANNY OF HYPOTHESES}

Most theories in physics do not test hypotheses in a natural way. Instead, they involve measuring values, or more com- monly, measuring functions. For example, I happen right now to be engaged in performing computations of the energy of a certain sort of antiferromagnet as a function of the strength of magnetic fields applied in two directions. Colleagues and I will compare these computations with experiments in which neutron beams bounced off magnetic samples under conditions of varying magnetic field (Muehlbauer et al., 2011). Searching the entire literature of condensed matter, the largest subfield of physics, you will rarely find the word "hypothesis," and you will almost never find the machinery of hypothesis testing - $t$ tests, $p$ values, and the like (Marder, 2010). In much of condensed matter physics, gathering data is cheap once an experiment is operational at all, so the response to random error is to take enough measurements to drive uncertainty down to desired levels. The scientific problems have to do with systematic error, identifying effects that explain functional relations.

Hypotheses are useful when a complex, noisy system is exposed to a small number of distinct treatments, and one wants to characterize their effects without knowing in detail how they work. Hypotheses become irrelevant when a system amenable to detailed mechanistic analysis is exposed to a continuous infinity of treatments.

As an example of a very simple case in which one can see these two modes of science in action, consider constructing an experiment with a light bulb and a light intensity sensor. A biological approach to this system might be to say "My hypothesis is that when the bulb is farther away the light will be dimmer." This idea would lead to an experiment in which a light bulb is placed at two different locations and intensity is measured multiple times. A low-quality version of the experiment would simply ask which case led to higher mean light intensity, while a higher-quality version would add a $t$ test for significance. Extensions of the experiment could ask whether yellow lights are brighter than green lights.

I have seen biologists nod contentedly at such a description of student-directed scientific progress, but physicists start to squirm. There is no point in checking whether the more distant light bulbs appear dimmer. It is obvious. In fact, with a little geometry, and using the concept of conservation of energy, the student should be able to predict the precise mathematical form of the functional dependence of light intensity upon distance to the sensor. For heaven's sake, do that, put some error bars on the measurement, and compare it with the expected power law.

It has often seemed to me that the difference in the approach to problems of physicists and biologists is great enough that, when given a battery and a bulb, a biologist will design a biology experiment and, when given a frog, a physicist will design a physics experiment (Geim, 1998).

In the battle for the hearts and minds of secondary school students, biologists win, and the victory is lasting. Many times, while I help college students construct what seems to me a perfectly good physics experiment, I see them turn and say almost in anguish, "But I don't know what my hypothesis is!" Students arrive in college with the strong intuition that science requires a hypothesis, an experiment, and minimal mathematics. Other ways of spending time are not science.

This singular view of the nature of science is creating several problems that lead back to STEM. Hidden within the "S" of science are wildly different modes of thought and action, all of them important. Despite the superficial glamor of 
physics, its mental processes are unfamiliar to most of the public and scarcely recognized as science at all. This may be part of the reason that physics enrollments are now at low enough levels that public universities may be increasingly unable to support undergraduate physics programs (Hodapp, 2011). Few entering undergraduates can imagine what they could learn in physics that would be of any use. The response to this situation is that physicists will have to be more deliberate in teaching and explaining important features of their discipline, just as biologists have long had to do.

There is even a threat, although more remote, to mathematics instruction at the secondary level. Deprived of contexts such as physics, mathematics at the level of algebra and above threatens to degenerate into a game. The public may not put up with the high stakes attached to this game forever (Hacker, 2012).

\section{IN THE END}

We have to approach STEM more as an opportunity than a threat. The opportunity is to identify a common core of scientific practices that integrate science, mathematics, engineering, and technology, and make this core a goal for every educated citizen. The Common Core Standards for Mathematics and the Next Generation Science Standards (Common Core State Standards Initiative, 2012; Achieve, 2013) appear to point in this direction.

Physics has a contribution to make that is separate from the inviolable list of topics from the introductory physics course. The way that physicists use mathematics in combination with experiment to construct causal models of the world should be part of the common core.

But the difficulties in moving toward this goal should not be ignored. We-the scientists, mathematicians, and engineers who will be asked to help implement the new standards-do not ourselves always possess the full set of skills that STEM education will ask of our students. We will struggle to prepare our own undergraduates, as well as current and future secondary teachers, to understand a curriculum broader than what we know. It is a struggle worth undertaking.

\section{ACKNOWLEDGMENTS}

I thank many colleagues across departments who have participated in the attempt to find a common core of knowledge and experience in scientific research for future teachers, particularly David Laude,
Pawan Kumar, Daniel Bolnick, Mary Walker, and Denise Ekberg. Development of the course text was partly supported by the National Science Foundation Program in Condensed Matter Theory and Materials Science, which does not endorse any of the opinions in this article.

\section{REFERENCES}

Achieve (2013). Next Generation Science Standards. http:// nextgenscience.org (accessed 22 April 2013).

Common Core State Standards Initiative (2012). Implementing the Common Core State Standards. http:/ / corestandards.org.

Evolution and the Nature of Science Institutes (2012). What IS the Nature of Science? www.indiana.edu/ ensiweb/nos.html (accessed 22 April 2013).

Geim A (1998). Everyone's magnetism. Phys Today 51, 36-39.

Hacker A (2012). Is algebra necessary? New York Times. http:/ / nyti .ms/ZiD0xU (accessed 22 April 2013).

Hodapp T (2011). The economics of education: closing undergraduate physics programs. APS News 20, 8. www.aps.org/ publications/apsnews/201112/backpage.cfm (accessed 22 April 2013).

Kitzmiller v. Dover (2005). Case no. 04cv2688, U.S. District Court for the Middle District of Pennsylvania. www.pamd.uscourts .gov/kitzmiller/kitzmiller_342.pdf.

Marder M (2010) Condensed Matter Physics, 2nd ed., Hoboken, NJ: Wiley-Blackwell.

Marder M (2011). Research Methods for Science, New York: Cambridge University Press.

McComas WF (2003). A textbook case of the nature of science: laws and theories in the science of biology. Int J Sci Math Educ 1, 141-155.

Muehlbauer S, Gvasaliya SN, Pomjakushina E, Zheludev A (2011). Double- $k$ phase of the Dzyaloshinskii-Moriya helimagnet $\mathrm{Ba}_{2} \mathrm{CuGe}_{2} \mathrm{O}_{7}$. Phys Rev B 84, 180406 .

PER Central (2012). PER Central Home Page. www.per-central.org (accessed 22 April 2013).

Reich ES (2011). Texas holds firm on physics closures. Nature. www.nature.com/news/2011/110924/full/news.2011.559.html (accessed 22 April 2013).

UTeach (2012). UTeach Home Page. http://uteach.utexas.edu (accessed 22 April 2013).

Wong SL, Hodson D (2008). From the horse's mouth: what scientists say about scientific investigation and scientific knowledge. Sci Stud Sci Educ 93, 109-130.

Wong SL, Hodson D (2010). More from the horse's mouth: what scientists say about science as a social practice. Int J Sci Educ 32, 1431-1463. 